\title{
An Integrated Approach of Using Polystyrene Foam as an Attachment System for Growth of Mixed Culture of Cyanobacteria with Concomitant Treatment of Copper Mine Waste Water
}

\author{
Venkatesh Chaturvedi, ${ }^{1}$ Monika Chandravanshi, ${ }^{2}$ \\ Manoj Rahangdale, ${ }^{2}$ and Pradeep Verma ${ }^{2,3}$ \\ ${ }^{1}$ School of Biotechnology, Banaras Hindu University, Varanasi, Ultar Pradesh 221005, India \\ ${ }^{2}$ Department of Biotechnology, Guru Ghasidas Vishwavidyalaya, Bilaspur, Chhattisgarh 495009, India \\ ${ }^{3}$ Department of Microbiology, Central University of Rajasthan, N.H. 8 Bandarsindri, Kishangarh, Ajmer, Rajasthan 305801, India
}

Correspondence should be addressed to Pradeep Verma; vermaprad@yahoo.com

Received 28 September 2013; Revised 8 December 2013; Accepted 8 December 2013

Academic Editor: David Bolzonella

Copyright ( $) 2013$ Venkatesh Chaturvedi et al. This is an open access article distributed under the Creative Commons Attribution License, which permits unrestricted use, distribution, and reproduction in any medium, provided the original work is properly cited.

\begin{abstract}
Cyanobacteria have tremendous applications in areas such as production of biofuels and pharmaceutically important pigments and are used as an adsorbent for the removal of toxic metabolites. However, large scale production of Cyanobacteria is not economically feasible due to high cost involved in separation of biomass. In this context, different attachment systems have been developed for the growth of Cyanobacteria on a solid support. In this study, a simple and economical attachment system using polystyrene foam for growth of Cyanobacteria has been presented. Results clearly indicate that high biomass yield can be obtained in attached system when compared to suspended system. In attachment system, the biomass yield showed $21.4 \%$, total protein content showed $29.2 \%$, chlorophyll content showed $11.1 \%$, and carotenoid content showed $13.1 \%$ increase as compared to the suspended system. The attachment system can also support the growth of Cyanobacteria in presence of copper mine waste water with concomitant removal of copper ions. These results were corroborated by COD analysis, which indicated significant reduction. Further, copper removal was high in attached system as compared to suspended system. It appears that attachment system offers protection for growing Cyanobacteria and can be effectively employed for growing Cyanobacteria in presence of waste water coming from different sources.
\end{abstract}

\section{Introduction}

Copper is considered as a persistent and ubiquitous environmental pollutant, which enters into the environment through anthropogenic and industrial activities $[1,2]$. Although copper is an essential trace element in animals, higher levels of copper ingested through contaminated water may lead to disastrous consequences in humans especially in children [3]. Therefore, efficient treatment of copper containing waste water is necessary for reducing its toxicity in living systems [4]. In this regard, many treatment processes have been developed which rely on physical phenomena such as adsorption, electrodialysis, and precipitation $[5,6]$. These methods have been shown to be expensive and time consuming. Therefore, biological removal of metal ions using microorganisms has been considered as a cheap and ecofriendly alternative $[7,8]$. Studies have shown that exopolysaccharides synthesized by Cyanobacteria act as biological ion-exchange materials [9] and can bind and remove metal ions [8, 10-12].

A major hindrance of utilizing Cyanobacteria is the high cost involved in its harvesting. Cultivation of Cyanobacteria is usually performed in open ponds or enclosed photobioreactors, where the yield is quite low [13]. To harvest Cyanobacteria from this solution, the cell suspension is usually concentrated by sedimentation or by flocculation; water is then removed from condensed slurry by evaporation [14]. Due to the huge size of the algal culture system, harvesting algal biomass from the dilute cell suspension is expensive [13]. 
Therefore, development of an attachment system, where Cyanobacteria are grown attached to a solid support system, seems to be an attractive alternative [14]. Many attached systems such as Algal Turf Scrubber (ATS) have been developed where Cyanobacteria/algae grow on a solid support [15]. However, this system requires high infrastructure and is practically not feasible in developing countries. There is a need to develop new attachment systems for large scale growth of Cyanobacteria that are economical and show ease in handling and maintenance [16-19]. Johnson and Wen [14] have developed a novel attachment system consisting of polystyrene foam as a solid support for growth of microalgae, which supported growth of Chlorella sp. on dairy manure waste water. In the present investigation, we have adopted polystyrene foam as a solid support for the growth of a mixed culture of Cyanobacteria isolated from paddy field. However, major modifications in the culturing of microalgae have been adopted so as to make it feasible for growing in areas where sufficient infrastructure is not available. Further, Cyanobacteria were grown in presence of more toxic copper mine waste water so that growth is achieved with concomitant removal of copper by growing mixed culture of Cyanobacteria $[12,20]$.

\section{Materials and Methods}

2.1. Strains and Culture Medium. Cyanobacteria employed in the present investigation were obtained from paddy fields situated at Bilaspur, in the state of Chhattisgarh, India. Cyanobacteria were maintained under sterile conditions in nitrogen free BG-11 medium [21] containing (g/L): $\mathrm{K}_{2} \mathrm{HPO}_{4}$. $3 \mathrm{H}_{2} \mathrm{O}, 0.04 ; \mathrm{MgSO}_{4} \cdot 7 \mathrm{H}_{2} \mathrm{O}, 0.075 ; \mathrm{CaCl}_{2} \cdot 2 \mathrm{H}_{2} \mathrm{O}, 0.036$; citric acid, 0.006; ferric ammonium citrate, 0.006; EDTA, 0.001; $\mathrm{NaNO}_{3}, 1.5 ; \mathrm{Na}_{2} \mathrm{CO}_{3}, 0.02$; and trace metal mix A5, $1.0 \mathrm{~mL}$. Trace metal mix A5 solution consisted of $(\mathrm{g} / \mathrm{L}) \mathrm{H}_{3} \mathrm{BO}_{3}, 2.86$; $\mathrm{MnCl}_{2} \cdot 4 \mathrm{H}_{2} \mathrm{O}, 1.81 ; \mathrm{ZnSO}_{4} \cdot 7 \mathrm{H}_{2} \mathrm{O}, 0.222 ; \mathrm{NaMoO}_{4} \cdot 2 \mathrm{H}_{2} \mathrm{O}$, $0.39 ; \mathrm{CuSO}_{4} \cdot 5 \mathrm{H}_{2} \mathrm{O}, 0.079$; and $\mathrm{CoCl}_{2} \cdot 6 \mathrm{H}_{2} \mathrm{O}, 0.05$. The culture was incubated at $26-30^{\circ} \mathrm{C}$ and $16 / 8 \mathrm{~h}$ photoperiod in a culture room under 3000 lux from cool white light.

2.2. Collection of Waste Water Sample. Water samples were collected from the copper mines located at Balaghat Malanjkhand, Madhya Pradesh, India. It is an open pit type mine owned by Hindustan Copper Limited (HCL). Geographical coordinates of Balaghat are $21^{\circ} 47^{\prime} 23.5248^{\prime \prime}$ North, $80^{\circ} 47^{\prime}$ 28.3344" East. Effluent from the Malnjkhand (HCL) plant is discharged to the tailing pond. Water samples were collected in autumn (February, 2012) from different spots of outlet1 and outlet 2 of the copper mining waste water reservoir. The copper mine wastewater was collected in a reservoir with total area of about $50 \mathrm{~m}^{2}$ and $1 \mathrm{~m}$ depth. Physiochemical properties of copper mine waste water from outlets were determined according to APHA (2005). The average effluent water quality is represented in Table 1.

2.3. Growth of Cyanobacteria in Attachment System. The substrate used for attachment of Cyanobacteria was polystyrene foam EPS $70(6 \mathrm{~cm} \times 12 \mathrm{~cm})$, fixed on the bottom of a growth chamber. Polystyrene foam EPS 70 was selected because it
TABLE 1: Physiochemical properties of copper mine waste water.

\begin{tabular}{|c|c|}
\hline Properties & Copper mine waste water \\
\hline Temperature & $38^{\circ} \mathrm{C}$ \\
\hline $\mathrm{PH}$ & 6.6 \\
\hline $\begin{array}{l}\text { Dissolve oxygen } \\
\left(\mathrm{mg} \mathrm{O}_{2} / \mathrm{L}\right)\end{array}$ & 14 \\
\hline $\begin{array}{l}\mathrm{BOD} \\
\left(\mathrm{mg} \mathrm{O}_{2} / \mathrm{L}\right)\end{array}$ & 4.0 \\
\hline $\begin{array}{l}\mathrm{COD} \\
\left(\mathrm{mg} \mathrm{O}_{2} / \mathrm{L}\right)\end{array}$ & 604.8 \\
\hline $\begin{array}{l}\text { Total dissolve solid } \\
(\mathrm{mg} / \mathrm{L})\end{array}$ & 217 \\
\hline $\begin{array}{l}\text { TSS } \\
(\mathrm{mg} / \mathrm{L})\end{array}$ & 120 \\
\hline $\begin{array}{l}\text { Alkalinity } \\
\left(\mathrm{CaCO}_{3} \mathrm{mg} / \mathrm{L}\right)\end{array}$ & 2000 \\
\hline $\begin{array}{l}\text { Acidity } \\
\left(\mathrm{CaCO}_{3} \mathrm{mg} / \mathrm{L}\right)\end{array}$ & 500 \\
\hline $\begin{array}{l}\text { Hardness } \\
\left(\mathrm{CaCO}_{3} \mathrm{mg} / \mathrm{L}\right)\end{array}$ & 240 \\
\hline
\end{tabular}

is of low cost and is widely used in packaging of various industrial and household goods and, after use, it is disposed as waste material. Therefore, it is readily available. The growth chamber was a plastic disposable bowl, which was covered by a polythene sheet. A glass tube was inserted through the sheet to provide aeration (Figure 1). Before inoculation, the whole setup was wiped twice with $70 \%$ ethanol and incubated under UV light for $30 \mathrm{~min}$. For suspended system, the same setup was employed without the use of polystyrene foam. The waste water from copper mine was filtered by using Whatman filter paper 1 and used directly without autoclaving. The growth chamber contained wastewater and BG-11 media in different combinations and was inoculated with microalgae culture grown in BG-11 medium at a concentration of $10 \%$ v/v. Copper mine waste water was mixed with BG-11 in different combinations, so as to achieve final concentration of $20 \%$, $40 \%$, and $60 \%$ copper mine waste water, respectively. Initial concentration of copper in waste water was $78 \mathrm{ppm}$; therefore, in $20 \%, 40 \%$, and $60 \%$ effluent waste water, the concentration of copper was $13.2 \mathrm{ppm}, 29.23 \mathrm{ppm}$, and $44.18 \mathrm{ppm}$, respectively. The growth chambers were incubated at $26-30^{\circ} \mathrm{C}$ and $16 / 8 \mathrm{~h}$ photoperiod in a culture room under 3000 lux from cool white light for 18 days. After 6, 12, and 18 days of incubation, the culture medium was decanted and the biomass was scrapped with the help of a scalpel and was freezedried. In suspended system, the medium was centrifuged at $10,000 \mathrm{rpm}$ for $10 \mathrm{~min}$ and cell pellet was freeze-dried.

2.4. Analytical Techniques. The protein content of freezedried biomass was determined by the modified Lowry method [22]. The chlorophyll a and carotenoid were determined according to Vonshak et al. [23]. For the estimation of copper, samples of $50 \mathrm{mg}$ of the freeze-dried biomass were mixed separately with $1 \mathrm{~mL}$ of aqua regia in covered $10 \mathrm{~mL}$ beakers. The samples were heated for another $1 \mathrm{hr}$ in water 

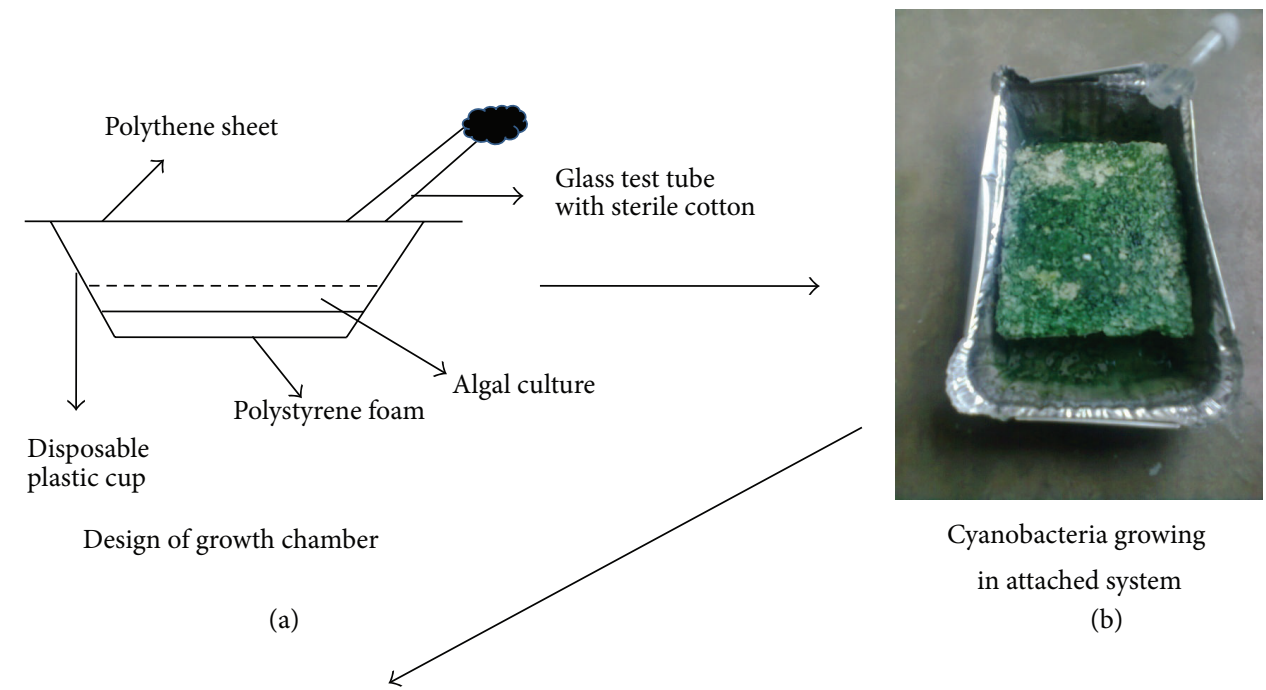

(b)

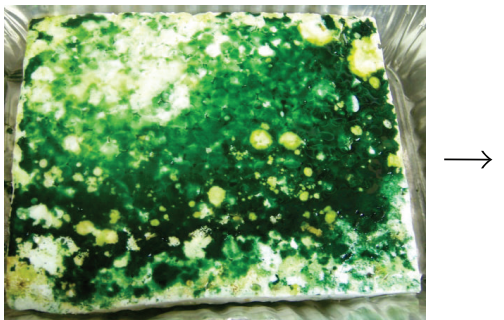

Growth of

Cyanobacterial mat

(c)

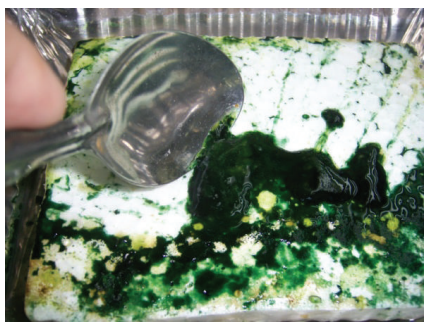

Recovery of biomass by scrapping

(d)

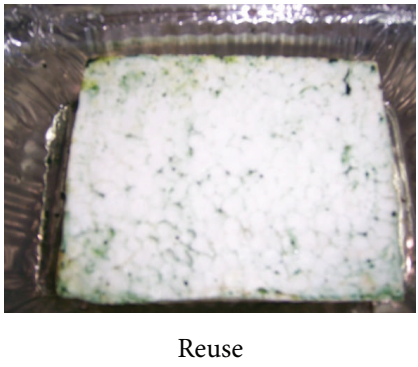

(e)

FIGURE 1: Development of an attachment system for the growth of mixed Cyanobacterial culture incubated at $26-30^{\circ} \mathrm{C}$ and $16 / 8 \mathrm{~h}$ photoperiod in a culture room under 3000 lux from cool white light. (a) Schematic representation of attachment system, (b) Cyanobacteria growing in the attachment system, (c) development of Cyanobacterial mat on the surface of polystyrene foam, (d) recovery of Cyanobacterial biomass by scrapping, and (e) reuse of attachment system for another cycle of growth.

bath and cooled. Then, volumetric flasks were filled with double deionized water to exactly $10 \mathrm{~mL}$ mark and left in shaker for overnight. The solution was analyzed with the flame atomic adsorption spectrophotometer 7000 (Shimadzu Corporation).

2.5. Microscopic Studies. Examination of mixed culture was under compound microscope (Nikon Eclipse E400, Nikon Corporation, Tokyo, Japan).

2.6. Statistical Analysis. All the results are expressed as mean \pm standard deviation. The results were analyzed using two-way ANOVA followed by post hoc analysis at $P>0.05$ confidence level.

\section{Results and Discussion}

3.1. Growth of Cyanobacteria. Figures 2(a) and 2(b) summarize the biomass yield and total protein content and Figures 3(a) and 3(b) summarize the chlorophyll a and carotenoid content obtained when algal cells were grown in attached and suspended system in the presence of different combinations of copper mine waste water, respectively. It was observed that in control containing BG-11, the yield in attached and suspended system in all the tested parameters was not significant $(P<0.05)$ after 6 days of incubation; however, after 12 and 18 days, the suspended system and the difference in yield become significant. The yield in suspended system after 18 days of incubation was low as compared to attached system. The biomass yield was $21.4 \%$, total protein content was $29.2 \%$, chlorophyll content was $11.1 \%$, and carotenoid content was $13.1 \%$ reduced as compared to the attached system. Similar results have been reported by Johnson and Wen [14]; in their study, Chlorella sp. was grown in both attached and suspended systems in presence of dairy manure waste water and high growth yield was obtained in attached system. In presence of different concentrations of copper mine waste water, the biomass yield showed gradual reduction and decreased in concentration dependent manner. It was observed that after 18 days of incubation, in attached system, biomass yield showed $33.8 \%, 42.2 \%$, and $67.8 \%$ reduction, total protein content showed $30.5 \%, 40.2 \%$, and $63.6 \%$ reduction, total chlorophyll content showed $14 \%$, $36.6 \%$, and $57.7 \%$ reduction, and carotenoid content showed $18.7 \%, 39.3 \%$, and $61.2 \%$ reduction in the presence of $20 \%$, 


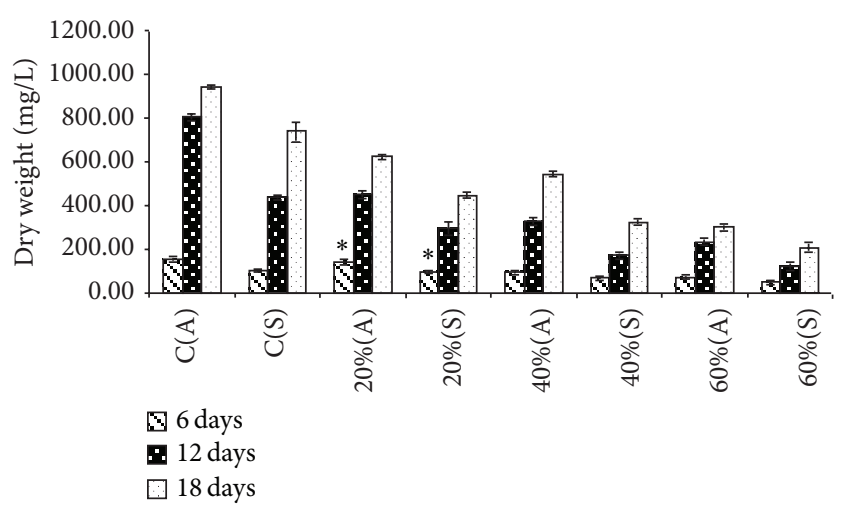

(a)

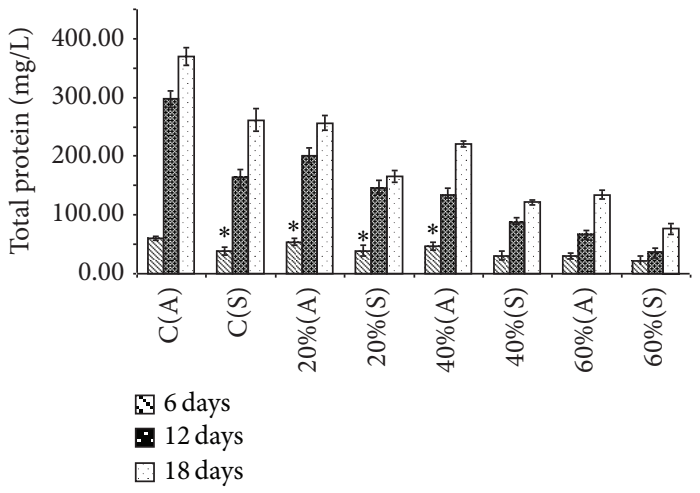

(b)

FiguRE 2: Biomass yield and protein content of mixed Cyanobacterial culture incubated at $26-30^{\circ} \mathrm{C}$ and $16 / 8 \mathrm{~h}$ photoperiod in a culture room under 3000 lux from cool white light. (a) Biomass yield and (b) total protein content of mixed Cyanobacterial culture in both attachment and suspended systems in presence of BG-11 growth medium and in presence of different concentrations of copper mine waste water. (A) represents attachment system and (S) represents suspended system, respectively. Values are represented as mean \pm standard deviation of three independent experiments.

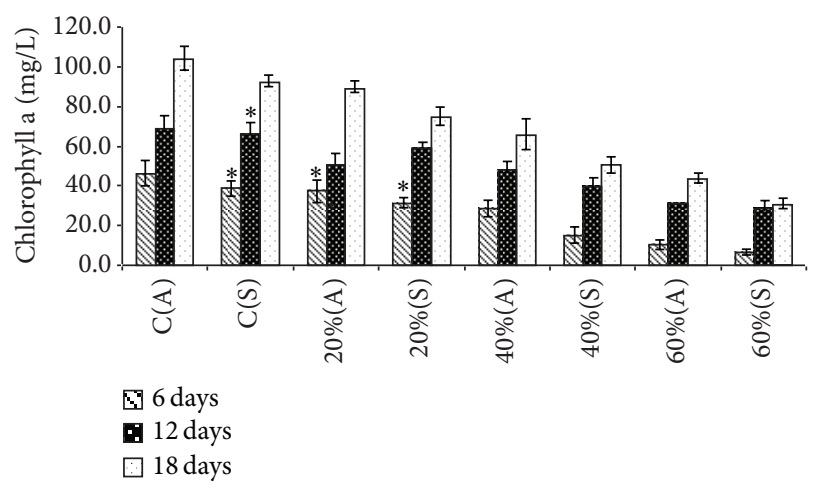

(a)

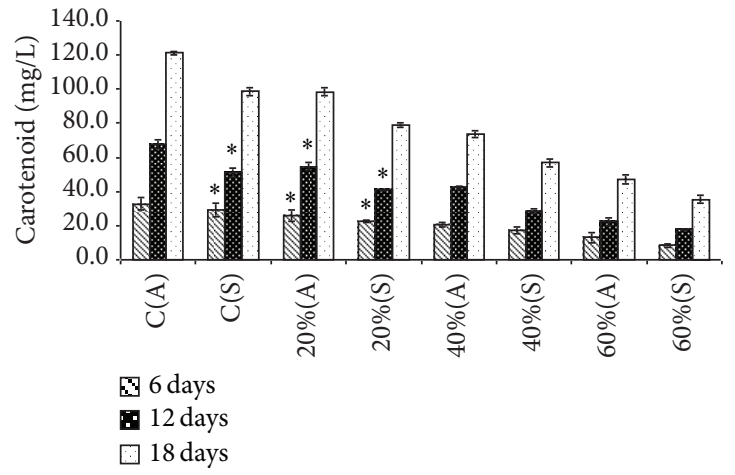

(b)

Figure 3: Chlorophyll a and carotenoid content of mixed Cyanobacterial culture incubated at $26-30^{\circ} \mathrm{C}$ and $16 / 8 \mathrm{~h}$ photoperiod in a culture room under 3000 lux from cool white light. (a) Chlorophyll a and (b) Carotenoid content of mixed Cyanobacterial culture in both attachment and suspended systems in presence of BG-11 growth medium and in presence of different concentrations of copper mine waste water. (A) represents attachment system and (S) represents suspended system, respectively. Values are represented as mean \pm standard deviation of three independent experiments.

$40 \%$, and $60 \%$ copper mine waste water, respectively. A similar trend was observed in suspended system also. In suspended system, after 18 days of incubation, biomass yield showed $39.4 \%, 56.2 \%$, and $71.7 \%$ reduction, total protein content showed $36.6 \%, 53.6 \%$, and $70.7 \%$ reduction, chlorophyll a content showed $18.7 \%, 45 \%$, and $66.5 \%$ reduction, and carotenoid content showed $20.1 \%, 42.3 \%$, and $64.1 \%$ reduction which was observed in presence of $20 \%, 40 \%$, and $60 \%$ copper mine waste water, respectively. It is noteworthy to mention that after 6 days of incubation, the reduction in $20 \%$ and $40 \%$ copper mine waste water was not so significant. However, after 12 days of incubation, the results were more pronounced. It is clear from the results that the reduction in all the parameters was more pronounced in suspended system than in attached system. This indicates that copper present in copper mine waste water is toxic to Cyanobacteria [2] and hence a dose-dependent reduction in growth occurs in the presence of copper ions [24]. However, our results also indicate that attached system offers protection for Cyanobacteria against copper toxicity. This is due to the fact the Cyanobacteria are attached to a solid support and hence encounter a less concentration of copper and therefore growth is favored. It clearly indicates that attached system is suitable for growth of Cyanobacteria in presence of toxic waste materials and aids in their removal. This is a significant advancement in the growth system developed by Johnson and Wen [14]. In their study, Chlorella sp. was grown in presence of less toxic dairy manure waste water with subsequent biomass production. In the present study, Cyanobacteria were grown in presence of more toxic copper mine waste water showing its removal.

3.2. Microscopic Examination of Cyanobacteria. The state of Chhattisgarh is well known for intense paddy cultivation. 
TABLE 2: Copper uptake from different concentrations of copper mine waste water by Cyanobacterial biomass after different time intervals in both attachment and suspended growth systems, incubated at $26-30^{\circ} \mathrm{C}$ and $16 / 8 \mathrm{~h}$ photoperiod in a culture room under 3000 lux from cool white light.

\begin{tabular}{|c|c|c|c|c|}
\hline \multirow[t]{2}{*}{ Culture system } & \multirow[t]{2}{*}{ Different effluent concentration } & \multicolumn{3}{|c|}{$\begin{array}{c}\text { Copper uptake (\%) } \\
\text { Incubation (days) }\end{array}$} \\
\hline & & 6 & 12 & 18 \\
\hline \multirow{3}{*}{ Attachment system } & $20 \%$ & $26.8 \pm 3.31$ & $44.7 \pm 3.18$ & $85.6 \pm 1.61$ \\
\hline & $40 \%$ & $34.2 \pm 2.21^{*}$ & $56.9 \pm 1.15^{*}$ & $88.9 \pm 1.25$ \\
\hline & $60 \%$ & $30.4 \pm 1.60$ & $42.5 \pm 0.91$ & $65.8 \pm 1.64^{*}$ \\
\hline \multirow{3}{*}{ Suspended system } & $20 \%$ & $20.5 \pm 1.32$ & $38.2 \pm 1.12$ & $70.3 \pm 1.54^{*}$ \\
\hline & $40 \%$ & $24.8 \pm 2.31$ & $45.3 \pm 1.12^{*}$ & $74.9 \pm 0.85$ \\
\hline & $60 \%$ & $19.2 \pm 1.41^{*}$ & $28.9 \pm 1.99^{*}$ & $53.8 \pm 1.27^{*}$ \\
\hline
\end{tabular}

Values are represented as mean \pm standard deviation of three independent experiments.

The values indicated by $\left({ }^{*}\right)$ are not significantly different from control at $P>0.05$, determined by two-way ANOVA followed by post hoc test.

In negative control, copper uptake by polystyrene foam was not detected in all combinations of copper mine waste water and BG-11.

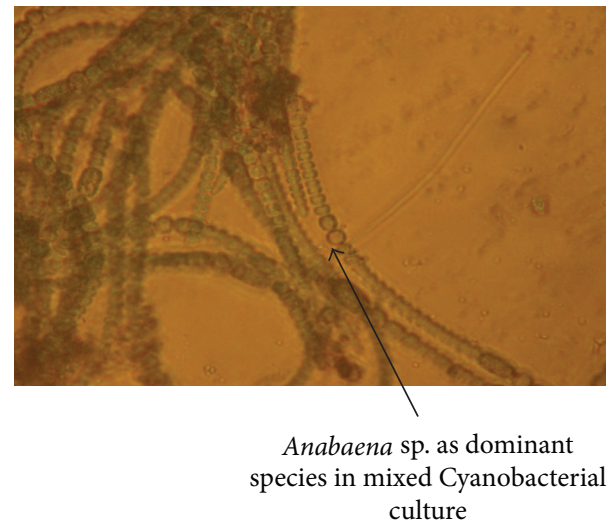

FIgURE 4: Microscopic examination of mixed Cyanobacterial culture in attachment system showing dominance of Anabaena sp. at 40X magnification.

Therefore, a mixed culture of Cyanobacteria was obtained from a paddy field situated at Bilaspur in the state of Chhattisgarh. Microscopic examination revealed that mixed culture contained Nostoc sp., Anabaena sp., and Chlorella sp. However, in the presence of different combinations of copper mine waste water, it was observed that Anabaena sp. was the dominant Cyanobacteria (Figure 4).

3.3. Removal of Copper Ions. The amount of copper removed by growing culture was also determined by estimating the uptake of copper in Cyanobacterial biomass after 6, 12, and 18 days of incubation. The results are represented in Table 2. It is clear from the results that growing Cyanobacteria effectively removed copper from culture medium. In both attached and suspended systems, an increase in copper removal was observed with an increase in growth of Cyanobacteria. Copper removal did not show significant increase $(P<0.05)$ with the increase of the copper concentration in the culture medium, that is, $20 \%$ and $40 \%$ concentration. However, at $60 \%$ concentration, a significant decrease $(P<0.05)$ in copper removal was observed. A similar trend was also
TABLE 3: Percent of reduction in COD from copper mine waste water by Cyanobacterial biomass.

\begin{tabular}{lcc}
\hline Culture system & $\begin{array}{c}\text { Different effluent } \\
\text { concentration }\end{array}$ & \% COD reduction \\
\hline \multirow{3}{*}{ Attachment system } & $20 \%$ & $56 \pm 1.8$ \\
& $40 \%$ & $53.2 \pm 2.2$ \\
Suspended system & $60 \%$ & $35.2 \pm 1.3^{*}$ \\
& $20 \%$ & $54.2 \pm 1.2$ \\
& $40 \%$ & $47.8 \pm 1.6$ \\
\hline
\end{tabular}

Values are represented as mean \pm standard deviation of three independent experiments.

The values indicated by $\left({ }^{*}\right)$ are not significantly different from control at $P>$ 0.05 , determined by two-way ANOVA followed by post hoc test.

observed in suspended system, but the amount of copper removed was significantly lower $(P<0.05)$ than attached system. This observation can be attributed to a decrease in growth of Cyanobacteria in both systems in presence of high concentration of copper. When amount of copper removed in attachment and suspended systems was compared, it was observed that amount of copper removed was more pronounced in attached system, when compared to suspended system. This was clearly due to high growth yield in attached system. Many reports have confirmed that exopolysaccharides synthesized by various Cyanobacteria are effective in removal of metal ions $[4,10,25]$. In attached system, the growing Cyanobacteria form a dense mat-like structure in which they retain the exopolysaccharides. However, in suspended system, these exopolysaccharides are lost in the culture medium and therefore they are not effective in absorbing the metal ions. In negative control, no adsorption of copper on polystyrene foam was observed. In order to estimate the efficacy of this process, percent of COD removal was estimated after 18 days of incubation. The results are depicted in Table 3. It is clear from the results that percent of COD removal in attachment system at $20 \%$ and $40 \%$ concentration ranged from 56 to $53.2 \%$ and in suspended system ranged from 54.2 to $47.7 \%$; at $60 \%$ concentration, the values were significantly 
$(P<0.05)$ lower in both attachment and suspended systems indicating toxicity of copper mine waste water to growing Cyanobacteria.

\section{Conclusions}

In this study, we have developed a simple and inexpensive attachment system for growth and harvesting of Cyanobacteria which can be employed for large scale culturing of Cyanobacteria in areas where sufficient infrastructure is not available. Cyanobacteria were grown in presence of copper mine waste water and showed significant removal of copper ions. Cyanobacterial biomass containing copper can be used for recovery of copper thus generating a value added product. This result clearly indicates that attached system offers protection for growing Cyanobacteria against toxic copper ions leading to a high biomass production with removal of copper from waste water. This result is an advancement of previous studies, where Cyanobacteria were grown on attached system in presence of less toxic wastes such as dairy manure waste water. We feel that this system can be effectively involved in treatment of toxic waste water with subsequent biomass production. Biomass can be employed for recovery of metal or for the extraction of value added products such as Cyanobacterial pigments and biofuel, thus generating employment opportunities.

\section{Conflict of Interests}

All the authors declare that they have no potential conflict of interests regarding the submission and publication of this paper.

\section{References}

[1] K. Gustavson and S.-Å. Wänberg, “Tolerance induction and succession in microalgae communities exposed to copper and atrazine," Aquatic Toxicology, vol. 32, no. 4, pp. 283-302, 1995.

[2] B. Debelius, J. M. Forja, T. A. Delvalls, and L. M. Lubián, “Toxicity of copper in natural marine picoplankton populations," Ecotoxicology, vol. 18, no. 8, pp. 1095-1103, 2009.

[3] H. D. Ozsoy and H. Kumbur, "Adsorption of $\mathrm{Cu}$ (II) ions on cotton boll," Journal of Hazardous Materials, vol. 136, no. 3, pp. 911-916, 2006.

[4] V. J. P. Vilar, R. J. E. Martins, C. M. S. Botelho, and R. A. R. Boaventura, "Removal of $\mathrm{Cu}$ and $\mathrm{Cr}$ from an industrial effluent using a packed-bed column with algae Gelidium-derived material," Hydrometallurgy, vol. 96, no. 1-2, pp. 42-46, 2009.

[5] S. Choudhary and P. Sar, "Characterization of a metal resistant Pseudomonas sp. isolated from uranium mine for its potential in heavy metal $\left(\mathrm{Ni}^{2+}, \mathrm{Co}^{2+}, \mathrm{Cu}^{2+}\right.$, and $\left.\mathrm{Cd}^{2+}\right)$ sequestration," Bioresource Technology, vol. 100, no. 9, pp. 2482-2492, 2009.

[6] C. Cojocaru, M. Diaconu, I. Cretescu, J. Savić, and V. Vasić, "Biosorption of copper(II) ions from aqua solutions using dried yeast biomass," Colloids and Surfaces A, vol. 335, no. 1-3, pp. 181188, 2009.

[7] K. Chojnacka, A. Chojnacki, and H. Górecka, "Biosorption of $\mathrm{Cr}^{3+}, \mathrm{Cd}^{2+}$ and $\mathrm{Cu}^{2+}$ ions by blue-green algae Spirulina sp.: kinetics, equilibrium and the mechanism of the process," Chemosphere, vol. 59, no. 1, pp. 75-84, 2005.
[8] J. Wang and C. Chen, "Biosorbents for heavy metals removal and their future," Biotechnology Advances, vol. 27, no. 2, pp. 195226, 2009.

[9] R. De Philippis, C. Sili, R. Paperi, and M. Vincenzini, "Exopolysaccharide-producing cyanobacteria and their possible exploitation: a review," Journal of Applied Phycology, vol. 13, no. 4, pp. 293-299, 2001.

[10] R. De Philippis, R. Paperi, and C. Sili, "Heavy metal sorption by released polysaccharides and whole cultures of two exopolysaccharide-producing Cyanobacteria," Biodegradation, vol. 18, no. 2, pp. 181-187, 2007.

[11] R. Paperi, E. Micheletti, and R. De Philippis, "Optimization of copper sorbing-desorbing cycles with confined cultures of the exopolysaccharide-producing cyanobacterium Cyanospira capsulata Cyanospira capsulata," Journal of Applied Microbiology, vol. 101, no. 6, pp. 1351-1356, 2006.

[12] D. Kumar and J. P. Gaur, "Metal biosorption by two cyanobacterial mats in relation to $\mathrm{pH}$, biomass concentration, pretreatment and reuse," Bioresource Technology, vol. 102, no. 3, pp. 25292535, 2011.

[13] E. M. Grima, E.-H. Belarbi, F. G. Acién Fernández, A. Robles Medina, and Y. Chisti, "Recovery of microalgal biomass and metabolites: process options and economics," Biotechnology Advances, vol. 20, no. 7-8, pp. 491-515, 2003.

[14] M. B. Johnson and Z. Wen, "Development of an attached microalgal growth system for biofuel production," Applied Microbiology and Biotechnology, vol. 85, no. 3, pp. 525-534, 2010.

[15] E. Kebede-Westhead, C. Pizarro, and W. W. Mulbry, “Treatment of swine manure effluent using freshwater algae: production, nutrient recovery, and elemental composition of algal biomass at four effluent loading rates," Journal of Applied Phycology, vol. 18, no. 1, pp. 41-46, 2006.

[16] A. Parmar, N. K. Singh, A. Pandey, E. Gnansounou, and D. Madamwar, "Cyanobacteria and microalgae: a positive prospect for biofuels," Bioresource Technology, vol. 102, no. 22, pp. 1016310172, 2011.

[17] C. Posten and G. Schaub, "Microalgae and terrestrial biomass as source for fuels-a process view," Journal of Biotechnology, vol. 142, no. 1, pp. 64-69, 2009.

[18] S. M. Mostafa, E. A. Shalaby, and G. I. Mahmoud, "Cultivating microalgae in domestic wastewater for biodiesel production," Notulae Scientia Biologicae, vol. 4, no. 1, pp. 56-65, 2012.

[19] Y. Su, A. Mennerich, and B. Urban, "Coupled nutrient removal and biomass production with mixed algal culture: impact of biotic and abiotic factors," Bioresource Technology, vol. 118, pp. 469-476, 2012.

[20] R. Chen, R. Li, L. Deitz, Y. Liu, R. J. Stevenson, and W. Liao, "Freshwater algal cultivation with animal waste for nutrient removal and biomass production," Biomass and Bioenergy, vol. 39, pp. 128-138, 2012.

[21] R. Rippka, J. Deruelles, J. B. Waterbury, M. Herdman, and R. Y. Stanier, "Generic assignments, strain histories and properties of pure cultures of cyanobacteria," Journal of General Microbiology, vol. 111, no. 1, pp. 1-61, 1979.

[22] M. A. Markwell, S. M. Haas, N. E. Tolbert, and L. L. Bieber, "Protein determination in membrane and lipoprotein samples: manual and automated procedures," Methods in Enzymology, vol. 72, no. C, pp. 296-303, 1981.

[23] A. Vonshak, Z. Cohen, and A. Richmond, "The feasibility of mass cultivation of Porphyridium," Biomass, vol. 8, no. 1, pp. 1325, 1985. 
[24] J. L. Levy, B. M. Angel, J. L. Stauber et al., "Uptake and internalisation of copper by three marine microalgae: comparison of copper-sensitive and copper-tolerant species," Aquatic Toxicology, vol. 89, no. 2, pp. 82-93, 2008.

[25] R. De Philippis, R. Paperi, C. Sili, and M. Vincenzini, "Assessment of the metal removal capability of two capsulated cyanobacteria, Cyanospira capsulata and Nostoc PCC7936," Journal of Applied Phycology, vol. 15, no. 2-3, pp. 155-161, 2003. 

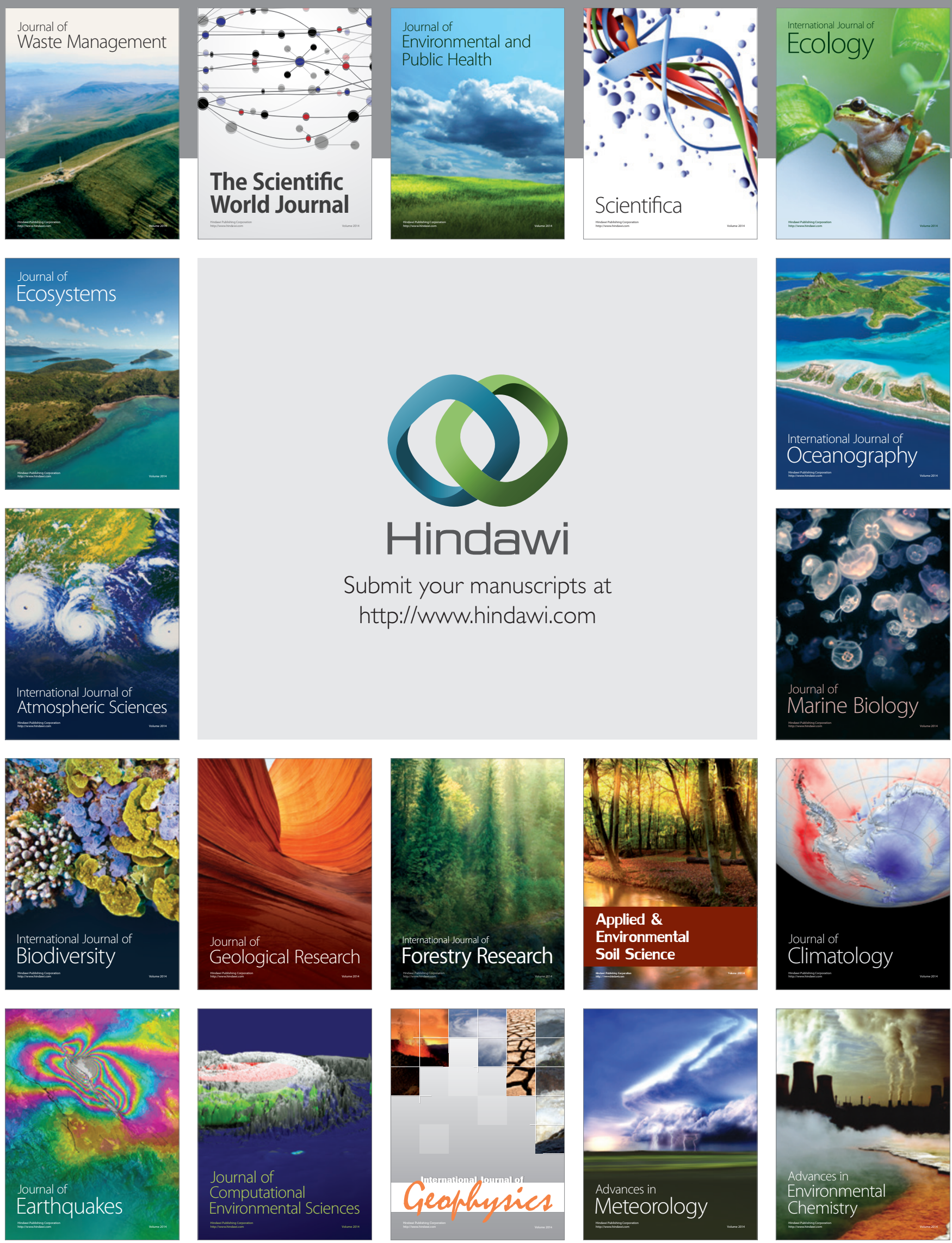